\title{
AUTOCONCEPTO ADOLESCENTE Y CLASE SOCIAL
}

\author{
Dr. AGUSTIN BUENO BUENO \\ Departamento de Psicología de la Salud, \\ Universidad de Alicante
}

\section{INTRODUCCION}

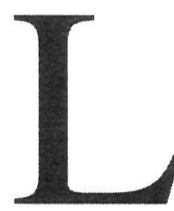

a imagen que cada uno tiene de sí mismo, a diferencia de otros constructos psicológicos, es en gran manera operativo. Procede de la acción, condicionándola y significándola. Por eso las diferencias entre los términos autoimagen, autoconcepto, autopercepción frente al de autoestima e incluso al de autoeficacia, son más bien conceptuales. En su expresión y en su influencia en la conducta fácilmente aparece un matiz evaluativo, de positividad o negatividad, de la propia imagen y de la ejecución (Coopersmith, S., 1967).

Bandura, A. (1986) señala tres fuentes posibles y combinables en la formación del autoconcepto:

- La valoración de la conducta del sujeto realizada por las figuras referenciales significativas para él (Rogers, C., 1959).

- La constatación de la propia experiencia y de las ejecuciones del sujeto.

- Los estereotipos relativos a un colectivo en el cual el sujeto se considere incluido.

Si tratamos de ponderar la influencia de estas tres fuentes en el autoconcepto de los adolescentes, podemos ver que, excluidos los elementos procedentes de estereotipos (a considerar en poblaciones concretas), la influencia de las valoraciones procedentes de las figuras referenciales es prioritaria sobre la constatación de las propias experiencias y ejecuciones. Cronológicamente han sido las valoraciones de los adultos quienes han hecho cristalizar un autoconcepto infantil concreto. Sobre este autoconcepto primario, y a través de la capacidad de autorreflexión adolescente, se puede empezar a formar una imagen de sí mismo basada en las propias constataciones. Teniendo en cuenta, no obstante, que la constatación de la propia experiencia durante el período adolescente es un fenómeno ambiguo, sometido a profundos altibajos de ejecución y 
de sensación. Estas experiencias, alternantes en signo e intensidad, van a ser también valoradas por las figuras referenciales, antiguas y nuevas.

Precisamente esa lógica sucesión cronológica hace que el autoconcepto primario predisponga en la ejecución y pueda determinar la autoevaluación de la misma. Quizás esté aquí una de las raíces de la crisis de identidad adolescente, si no en los términos estrictos de Erickson $(1968,1975)$, sí en cuanto expresión de la disparidad entre las valoraciones previas y las actuales procedentes del grupo de iguales, y, por tanto, más cercanas a las apreciaciones del sujeto.

Desde esta misma perspectiva, el autoconcepto procedente de las figuras referenciales es un reflejo de los valores, estilos de vida y códigos normativos del contexto social en que se ha criado y desarrollado el muchacho. Por esta razón es coherente pensar que el estatus socioeconómico (ESE), como exponente del contexto social, esté relacionado con el autoconcepto (Lal, J. N., 1987; Martín, J. y Redmore, C., 1978); aunque no ha sido esta afirmación la constante en los trabajos de investigación. Coopersmith, S. (1968), Murphy, E. J. (1976), Marsh, L. K. (1975) no encuentran relación entre ambas variables con las muestras y pruebas que ellos utilizan. Unas veces las muestras no determinan grupos sociales suficientemente diferenciados, y otras veces las pruebas empleadas sólo tangencialmente aprecian algún aspecto de autopercepción.

\section{METODO}

\subsection{Objetivo}

Dentro de un estudio más amplio (Bueno, A., 1990a) se ha estudiado la relación entre clase social y conflictividad del autoconcepto en adolescentes varones. Se intentaba ver si las experiencias derivadas de la diferente situación sociocultural podían tener alguna repercusión en la imagen de sí mismo, tanto a nivel global como en aspectos concretos.

\subsection{Variables y muestras}

Junto a pruebas como el Raven, Inteligencia Social de O'Sullivan y Guilford (1978), EPQ-J y ETS (Valverde, J., 1980), se ha aplicado a 180 adolescentes varones un Cuestionario de Indices de Conflicto 
(CIC) de elaboración propia, en el cual se exploran la conflictividad de las imágenes paterna y materna (CIP y CIM) y la conflictividad de la imagen de sí mismo (CIS). Esta parte del cuestionario incluye las siguientes facetas de autoconcepto: simpatía-antipatía, fortaleza física-debilidad, autoagrado estético-desagrado, alegría-tristeza (habituales), estatura, inteligencia, personalidad «rara», considerarse querido, considerarse objeto de burlas, perspectiva de vida futura optimista-pesimista.

La muestra estaba dividida en dos grupos de 90 sujetos cada uno, diferenciados por el Indice de Características de Estatus (ICS) obtenido a partir de las puntuaciones agrupadas del nivel de instrucción y profesión de padre y madre (Dpto. de Psicología Diferencial y del Trabajo de la Univ. Complutense). Uno de estos grupos constituye la Muestra M (ICS >9), representativa de la población de clase media; y el otro la Muestra A (ICS <7), representativa de los estratos socioculturales menos desarrollados. En el resto de variables: edad (11-15 años), sexo, nivel de estudios y tipo de centro escolar $\left(6 .^{\circ}, 7 .^{\circ}, 8 .^{\circ}\right.$ EGB de Colegios Públicos de Alicante), persona y forma de aplicación, ambos grupos estaban perfectamente igualados.

\subsection{Tratamiento estadístico}

Se ha obtenido la significación de la diferencia entre las medias de una y otra muestra así como la dependencia de las puntuaciones $\left(\mathrm{Ji}^{2}\right)$, respecto a la pertenencia a una u otra muestra en CIS (Conflictividad de la imagen de Sí Mismo).

También se han obtenido las correlaciones entre las distintas pruebas utilizadas en una y otra muestra.

\section{RESULTADOS OBTENIDOS}

3.1. Significación de la diferencia entre las medias de ambas muestras en CIS

CUADRO 1

\begin{tabular}{|c|c|c|c|c|c|}
\hline & Media & Sigma & Diferencia & $t$ & $p$ \\
\hline Muestra M & 3.822 & 2.524 & \multirow{2}{*}{-1.155} & \multirow{2}{*}{2.840} & \multirow{2}{*}{$<, 01$} \\
\hline Muestra A & 4.977 & 2.891 & & & \\
\hline
\end{tabular}




\subsection{Dependencia de las puntuaciones respecto a la pertenencia a} una u otra muestra

\section{CUADRO 2}

$$
\mathrm{Ji}^{2}=9,00^{*} \quad \text { g.1.:1 } \quad \mathrm{p}<, 01
$$

* Obtenido en base a la dicotomización de ambas muestras en función de la media

\subsection{Correlaciones de CIS con las restantes pruebas en ambas} muestras

\begin{tabular}{|c|c|c|c|c|c|c|c|c|c|}
\hline & $I G$ & $I S$ & $N$ & $E$ & $P$ & $C A$ & ETS & $C I P$ & $C I M$ \\
\hline Muestra M &,- 16 &,- 01 &, 11 &, 05 & ,16 &, 12 &, $23 *$ &, 07 &, 17 \\
\hline Muestra A &,$- 23 *$ &,- 15 &, $30^{* *}$ &, $25 * *$ & ,12 & ,09 & , 10 & ,13 &, $25^{* *}$ \\
\hline
\end{tabular}

IG: Inteligencia General, Raven

IS: Inteligencia Social, Guilford

$\mathrm{N}$ : Neuroticismo (EPQ-J)

E: Extraversión (EPQ-J)

P: Psicoticismo (EPQ-J)

CA: Conducta Antisocial (EPQ-J)

ETS: Escala Tendencias Sociales

CIP: Conflicto. con Imagen Paterna

CIM: Conflicto. con Imagen Materna

\section{COMENTARIO Y DISCUSION DE LOS RESULTADOS}

Los datos reflejados en los Cuadros 1 y 2 indican que la conflictividad de la imagen de sí mismo en la adolescencia no es independiente de la pertenencia a una clase social o a otra. Lógicamente hablamos de la conflictividad representativa de los grupos sociales estudiados. Por tanto hay que dejar a salvo las diferencias en CIS dentro de un mismo grupo, que no son atribuibles a las pequeñas diferencias de estatus existentes en él.

Por otra parte la consideración del autoconcepto como valoración global de diversos aspectos es interesante como síntesis o balance personal, donde aspectos positivos quedan contrarrestados por otros negativos (conflictivos) y viceversa. Un autoconcepto de valoración global conflictiva nos indica que los aspectos negativos han predominado sobre los positivos; pero en la actividad diaria y en la intervención esto tiene un alcance relativo. El estudio del autoconcepto es operativo (Bandura, A., 1986) en la medida en que señale las facetas de uno y otro signo. 
Los aspectos en los cuales los chicos de la muestra A (estatus socioeconómico inferior) se han manifestado con un autoconcepto más conflictivo que los de la muestra $\mathrm{M}$ han sido: considerarse poco listos, un poco raros, objeto de burlas, y con perspectiva de vida difícil. En cambio, los de la muestra de clase media se han valorado con más frecuencia como: tristes y débiles.

En el Cuadro 3 podemos apreciar que las correlaciones entre CIS y las restantes pruebas aplicadas se incrementan, manteniendo el signo, cuando se trata de la muestra de clase social inferior; con excepción de las obtenidas en P, CA y ETS, que pudimos apreciar que en cuanto exponentes de conductas inadaptadas tenían un comportamiento distinto según la clase social (Bueno, A., 1990b).

El rendimiento intelectual, tanto general como social, presenta una correlación negativa respecto al autoconcepto conflictivo. Esto, si bien no debe interpretarse en términos de causa-efecto en ninguna dirección, sí hay que considerarlos mutuamente influidos y relacionados con la variable común de estatus (ESE).

A la inversa, los rasgos de personalidad (Neuroticismo e Introversión), así como la conflictividad de las imágenes parentales, están correlacionadas con CIS de manera directa y elevada.

Todo esto, por una parte, nos confirma que el autoconcepto es una variable sintetizadora de las características del sujeto; y, por otra, nos indica que el ESE bajo es un factor influyente, o mejor subyacente, en la percepción conflictiva de sí mismo y en el desarrollo intelectual y de la personalidad.

Si tratamos de indagar el fundamento de la relación aparecida entre clase social y autoconcepto conflictivo, veremos que difícilmente puede descubrirse una relación lineal (Forteza, J. A., 1981), como en general ocurre con todos los paralelismos entre variables sociales, o estructurales, y variables psicológicas. Hay que pensar en variables intermedias, en el carácter funcional de cada medio social, o estilos de vida, como determinantes de tal paralelismo. En la medida en que son los criterios valorativos de las figuras referenciales la fuente primordial del autoconcepto, los estilos de vida, en cuanto formas de funcionar y desenvolverse los adultos en ese medio social, condicionarán los criterios de valoración.

Precisamente Coopersmith, S., aunque no encontraba relación entre ESE y autoconcepto, ya que delimita el estatus por ingresos dentro de la misma clase media, llega a una conclusión semejante a la nuestra. A la hora de describir el clima familiar de los chicos con baja autoestima lo retrata así:

«(Padres) extremadamente permisivos pero inflingían castigos severos cuando los chicos les molestaban. Estos consideraban a sus padres injustos, y... faltos de interés hacia ellos.»

En cambio en los chicos de alta autoestima: 
«(Los padres) exigían altos niveles de conducta, eran estrictos y constantes en el cumplimiento de las normas. Pero su disciplina no se apoya en medios severos... Usaban recompensas más que castigos, y sus hijos alababan su imparcialidad.» (Coopersmith, S., 1968, pág. 99).

Ambas descripciones son reveladoras de dos estilos de vida bien distintos, y al mismo tiempo fácilmente identificables con los más frecuentes en niveles socioculturales bajos y medios, respectivamente. Por supuesto, los estilos de vida no son estrictamente asimilables a los niveles socioculturales, pero sí que hay constantes claras y mayoritarias en uno y otro nivel social. Lo mismo ocurre con la conflictividad del autoconcepto y con otras muchas facetas comportamentales.

\section{BIBLIOGRAFIA}

Bandura, A.: Social foundations of thought and action. Englewood Cliffs, Nueva York, 1986: Prentice Hall (Trad. Barcelona, Martínez Roca, 1987).

Bueno, A.: Carencia económica y distorsión familiar en la adolescencia. Editorial de la Universidad Complutense, Madrid, 1990a.

-: «La teoría de la criminalidad de Eysenck: dos lecturas en función de la clase social». Delincuencia/Delincuency, 2, 1, págs. 37-50, $1990 \mathrm{~b}$.

Coopersmith, S.: The antecedents of self-esteem. Freeman, San Francisco, 1967.

—: «Studies in self-esteem». Scientific American, 218, 2, págs. 96-106, 1968.

Erickson, E.: Identity: youth and crisis. Norton, Nueva York, 1968.

—: Life, history and the historical moment. Norton, Nueva York, 1975.

Forteza, J. A.: «Inteligencia y medio ambiente». En: Psicologia y medio ambiente. Varios. MOPU, págs. 124-149, Madrid, 1981.

Lal, J. N.: «Social class differences in self perception». Perspectives in Psychological Researchs, 10, 2, págs. 30-36, 1987.

Marsh, L. K.: «Self-esteem, achievement responsability, and reading achievement of lowerclass black, white, and hispanic seventh-grade boys». Dissertation Abstracts International, 35, 10-A, págs. 6514-6515, 1975.

Martin, J. y Redmore, C.: «A longitudinal study of ego development». Developmental Psychology, 14, 2, págs. 189-190, 1978.

Murphy, E. J.: «Sel-concept changes in low socioeconomic children as a function of decentralized, residential camping experiences». Dissertation Abstracts International, 37, 6-a, pág. 3526, 1976.

O'Sullivan, M. y Guilford, J. P.: Les tests d'intelligence sociale: Manuel. Editions du Centre de Psychologie Appliquée, París, 1978 (Original en Orange, California, Sheridan Psychological Services, 1976).

Rogers, C.: «A theory of therapy, personality, and interpersonal relationships, as developed in the client-centered framework». En Psychology: a study of a science vol. III: Formulations of the person and the social context. Koch, S. (ed.). McGraw-Hill, Nueva York, págs. 184-256, 1959.

Valverde, J.: El proceso de inadaptación social en el adolescente. Facultad de Psicología. Univ. Complutense (Tesis Doctoral), Madrid, 1980. 